\title{
Athletes now span every demographic
}

\section{Stephen A Margolis}

No human is limited.

The importance of physical activity as a core component of the suite of preventive measures central to improving health outcomes has been documented since the Ancient Greek period. ${ }^{2}$ Yet, the headline news regarding Australian physical activity trends highlights that only $15 \%$ (2.8 million) of people aged $\geq 18$ years meet the minimum activity guidelines for physical activity and muscle strengthening. ${ }^{3,4}$

What do we know about this apparently select group? Anderson reports that global participation in running has risen by $58 \%$ in the past 10 years to 7.9 million people, with the primary motivation appearing to move from an achievement to a psychological, health and social focus. ${ }^{5}$ Female runners now outnumber male runners, with older runners becoming more common. ${ }^{5}$ There is also evidence that less experienced runners are increasingly attracted to the sport. Hence, athletes no longer fall into the stereotyped demographic and include those who might appear at first glance least likely, such as women aged $>60$ years.

Sports that are more technical are also rising in popularity; for example, Triathlon Australia reported 35,614 participants in 2018 - a 30\% increase from 2017 - plus an additional 36,000 children in Triathlon Australia-branded school events. ${ }^{6}$

How many of these participants are athletes? There are four required criteria, which are not overly onerous: ${ }^{7,8}$

- the participant is training to improve performance

- the individual participates in competitions

- the participant is a member of a sports club

- the sport is a major focus of interest.

In light of these criteria, it can be seen that athletes are found across the entire population demographic spectrum.

From a general practitioner (GP) perspective, this means that their patient base may include a number of athletes. Therefore, it may be helpful to clarify whether patients are athletes, as this may affect the nature of advice and treatment.

The science behind the management of athletes with injury or illness has exploded over the past two decades. A key finding has been that the historically popular advice to sick or injured athletes to stop physical activity pending recovery is now not recommended. For example, Fallon discusses training load modification rather than cessation for a number of common overuse syndromes. ${ }^{9}$ As sport is a major area of focus in athletes' lives, it is easy to see how overplaying rest will be received, as this apocryphal dialogue suggests:

\section{Doctor: 'You need to rest that injured leg for at least two weeks.'}

\section{Runner: 'Of course, after I run home first!'}

Another important change is the role of ultrasonography and magnetic resonance imaging in diagnosing the exact nature of sports injuries, as detailed by Jyoti and colleagues. ${ }^{10}$ For example, the exact location and grade of muscle tears can now be easily identified, which provides important information for training modification and physical therapy programs.

In summary, consideration of lifestyle is an important component of the clinical interaction GPs have with their patients. Although the vast majority of Australians may benefit from encouragement to increase exercise, there is a significant group of keen participants across all demographics. It is important to identify members of this group as their medical needs and compliance with treatment recommendations may be quite different and need to be adjusted accordingly.

\section{Author}

Stephen A Margolis, OAM; Editor in Chief, Australian Journal of General Practice; Professor, School of Medicine, Griffith University, Qld; Staff Specialist, Royal Flying Doctor Service.

\section{References}

1. Willemsen E. 'No Human Is Limited': Kipchoge Runs Sub-2 Hour Marathon. Bloomberg. 12 October 2019. Available at www.bloomberg.com/ news/articles/2019-10-12/kipchoge-is-firstto-dip-under-2-hours-for-marathon [Accessed 15 December 2019].

2. Margolis SA. Preventive healthcare: A core component of Australian general practice. Aust J Gen Pract 2018;47(12):821. doi: 10.31128/AJGP-1118-4751.

3. Australian Institute of Health and Welfare. Insufficient physical activity. Cat no PHE 248. Canberra: AlHW, 2019. Available at www.aihw. gov.au/reports/risk-factors/insufficient-physicalactivity [Accessed 8 December 2019].

4. Australian Bureau of Statistics. Australian Demographic Statistics, June 2016. Cat no 3101.0. Canberra: ABS, 2016. Available at www.abs.gov.au/AUSSTATS/abs@.nsf/ Lookup/3101.0Main+Features1Jun\%20 2016?OpenDocument [Accessed 15 December 2019].

5. Andersen JJ. The State of Running 2019. Fort Collins, CO: RunRepeat.com and the International Association of Athletics Federations, 2019. Available at https://runrepeat.com/state-ofrunning [Accessed 15 December 2019].

6. Triathlon Australia. Annual Report 2017-2018. Surry Hills, NSW: Triathlon Australia, 2018 Available at www.triathlon.org.au/Assets/Triat hlon+Australia+Digital+Assets/2017-2018+Tria thlon+Australia+Annual+Report.pdf [Accessed 15 December 2019].

7. Araújo CG, Scharhag J. Athlete: A working definition for medical and health sciences research. Scand J Med Sci Sports 2016;26(1):4-7. doi: 10.1111/sms.12632.

8. Brun S. Some current challenges facing the athlete and their doctor. Aust J Gen Pract 2020;49(1-2):23-31.

9. Fallon K. Overuse injuries in the athlete. Aust J Gen Pract 2020;49(1-2):7-11.

10. Jyoti $R$, Jain $T$, Damiani $M$. The expanding role of imaging in the diagnosis and management of sports injuries. Aust J Gen Pract 2020;49(1-2):12-15. 